\title{
Studi Kinerja Bandar Udara Binaka Gunungsitoli
}

\author{
Nofan Fortin TAFONAO ${ }^{1}$ Charles SITINDAON ${ }^{2}$ \\ ${ }^{1}$ Program Studi Teknik Sipil, Universitas Katolik Santo Thomas \\ ${ }^{2}$ Staf Pengajar Teknik Sipil, Universitas Katolik Santo Thomas, email: charles_sitindaon@yahoo.co.id
}

\begin{abstract}
Analysis Gunungsitoli Binaka needed due to meet the needs of passengers, the higher the growth rate of passengers who arrive and leave it needs the land side and air side of the airport would be more dense, so it takes a further expansion. One development that is done is to increase the need for landside and airside. This study aims to determine the needs of the land side (terminal passengers) and air side for the next 20 years. The method used in this research is a quantitative method that follows the ISO standardization, SKEP, FAA and ICAO. The results of this study show that the departing passengers in 2038 amounted to 338732 people and the passengers who come numbered 315267 people. At peak hours ( peak hour) number of passengers departed for 440 people and the number of passengers who come as much as 410 people. For departing aircraft movements that occurred in 2038 amounted to 6,241 movements. With a temperature of $29.3{ }^{\circ} \mathrm{C}$ Binaka produce 2,637 meter long runway for the aircraft types 737-800, with wide Needs taxiway 18 meter.
\end{abstract}

Kata kunci: terminal building, runway, taxiways, apron, plane

\begin{abstract}
Abstrak
Analisis terhadap kebutuhan sisi darat dan sisi udara Bandara Gunungsitoli Binaka diperlukan untuk memenuhi kebutuhan yang semakin tinggi tingkat pertumbuhan penumpangnya. Salah satu pengembangan yang dilakukan adalah melakukan ekspansi sisi darat dan udara. Penelitian ini bertujuan untuk mengetahui kebutuhan sisi darat (penumpang terminal) dan sisi udara untuk 20 tahun ke depan. Metode yang digunakan dalam penelitian ini adalah metode kuantitatif yang mengikuti standarisasi ISO, SKEP, FAA dan ICAO. Hasil penelitian ini menunjukkan bahwa penumpang yang berangkat tahun 2038 berjumlah 338.732 orang dan penumpang yang datang berjumlah 315.267 orang. Pada jam sibuk (peak hour) jumlah penumpang berangkat sebanyak 440 orang dan jumlah penumpang yang datang sebanyak 410 orang. Untuk pergerakan pesawat berangkat yang terjadi pada 2038 berjumlah 6.241 pergerakan. Dengan diketahui temperatur lingkungan sebesar $29,3^{\circ} \mathrm{C}$, Bandara Gunungsitoli Binaka menghasilkan kebutuhan landasan pacu minimum sepanjang 2.637 meter untuk pesawat jenis 737-800, dengan lebar taxiway 18 meter.
\end{abstract}

Kata kunci: terminal, runway, taxiway, apron, pesawat terbang

\section{Pendahuluan}

Bandar udara Binaka Gunungsitoli merupakan Bandar Udara satu-satunya di Pulau Nias. Bandara yang terletak di Kecamatan Gunungsitoli ini memiliki panjang landas pacu $2.250 \mathrm{~m}$ sehingga memungkinkan bagi pesawat seperti ATR dan sejenisnya untuk bisa mendarat di Bandar Udara Binaka Gunungsitoli.

Sesuai dengan peraturan Direktur Jenderal Perhubungan Udara Nomor : SKEP/77/VI/2005 tentang Persyaratan Teknis Pengoperasian Fasilitas Teknik Bandar Udara, memuat tentang ketentuan umum, persyaratan teknis pengoperasian fasilitas sisi udara (runway, taxiway, apron); persyaratan teknis pengoperasian fasilitas sisi darat (terminal penumpang, terminal barang, bangunan operasi, fasilitas penunjang bandar udara); peralatan pemeliharaan fasilitas teknik bandar udara dan persyaratan teknis pengoperasian fasilitas teknik bandar udara (Bandar Udara Khusus Perairan, Elevated Heliport, Surface Level Heliport, dan Helideck).

\footnotetext{
" pengarang koresponden
} 
Maksud penelitian untuk melakukan Studi Kenerja Bandar Udara Binaka Gunungsitoli berdasarkan peraturan Direktur Jendral Perhubungan Udara dan bertujuan mengevaluasi kondisi eksisting fasilitas sisi darat dan sisi udara Bandara Binaka Gunungsitoli berdasarkan SKEP/77/VI/2005 tentang Persyaratan Teknis Pengoperasian Fasilitas Teknik Bandar Udara terhadap Sistem operasional. Selanjutnya untuk mengetahui pergerakan Lalu Lintas Angkutan Udara (LLAU) untuk 20 tahun mendatang, mengetahui kebutuhan fasilitas sisi darat dan sisi udara bandara setelah di-forecasting.

Ruang lingkup penelitian yang dilaksanakan adalah mengevaluasi terminal keberangkatan dan kedatangan penumpang; Bandara sisi darat meliputi gedung terminal Keberangkatan (Hall keberangkatan, Ruang tunggu, Check-in area, Check-in counter, Tempat duduk, Toilet) sedangkan untuk terminal Kedatangan meliputi (Baggage Conveyor Belt, Baggage Claim Area, Hall Kedatangan dan Toilet); Bandara sisi udara meliputi runway, taxiway dan apron.

\section{Bandar Udara dan Kelengkapannya}

\section{Pengertian Bandar Udara}

Bandar udara adalah prasarana transportasi udara yang mempunyai berbagai fasilitas untuk melayani pendaratan dan tinggal landas pesawat terbang, bongkar muat barang maupun penumpang, pengisian bahan bakar, penyimpanan serta perbaikan pesawat. Dalam merencanakan maupun menganalisa suatu Bandar Udara yang paling penting ditinjau adalah seimbangnya antara kebutuhan (demand) dan permintaan (supply) pada tahun rencana. Sistem bandar udara dibagi dua yaitu Sisi darat (land side) dan Sisi udara (air side).

\section{Dasar-Dasar Perencanaan Bangunan Terminal Penumpang}

Berdasarkan SNI 03-7046-2004 tentang terminal penumpang Bandar Udara dalam menerapkan persyaratan keselamatan operasi penerbangan, bangunan terminal dibagi dalam tiga kelompok ruangan, yaitu ruangan umum, ruangan semi steril, ruangan steril

Faktor yang mempengaruhi besaran bangunan terminal penumpang ini antara lain:

1. Jumlah pelayanan penumpang per tahun.

2. Jumlah penumpang waktu sibuk yang akan menentukan besaran ruang-ruang pada bangunan terminal penumpang.

Berikut klasifikasi terminal Bandar udara berdasarkan jumlah penumpang waktu sibuk seperti digambarkan pada Tabel 1. Terlihat berdasarkan penumpang dan jumlah penumpang yang berpindah pada jam sibuk sesuai dengan peraturan terminal.

Tabel 1. Klasifikasi Terminal Bandara Berdasarkan Jumlah Penumpang Waktu Sibuk

\begin{tabular}{|c|c|}
\hline Penumpang Waktu Sibuk (orang) & Jumlah Penumpang Transfer (orang) \\
\hline$\geq 50$ (terminal kecil) & 10 \\
\hline $101-500$ (terminal sedang) & $11-20$ \\
\hline $501-1500$ (terminal menengah) & $21-100$ \\
\hline $501-1500$ (terminal besar) & $101-300$ \\
\hline
\end{tabular}

\section{Standar Luas Terminal Keberangkatan}

Standar minimal luas ruang terminal keberangkatan ditentukan sesuai dengan persyaratan teknis dari kebutuhan ruang pada fasilitas-fasilitas sisi darat yang mengacu pada standar IATA yang di jelaskan pada Tabel 2. 
JURNAL REKAYASA KONSTRUKSi MEKANiKA SipIL (JRKMS)

Vol.3 No.1 April 2020

p-ISSN 2614-5707 e-ISSN 2715-1581

Tabel 2. Standar Luas Terminal Keberangkatan

\begin{tabular}{|c|c|c|}
\hline No & Jenis Fasilitas & Kebutuhan Ruang \\
\hline 1 & Kerb Keberangkatan & 0.096.a.p. $(+10 \%)$ \\
\hline 2 & Hall Keberangkatan & $A=[0,75\{a(1+f)+b\}](+10 \%)$ \\
\hline 3 & Ruang Tunggu Keberangkatan & $A=\left(C-\frac{u . i+v \cdot k}{30}\right) m^{2}(+10 \%)$ \\
\hline 4 & Check-in Area & $A=0,25(a+b) m^{2}(+10 \%)$ \\
\hline 5 & Check-in Counter & $\mathrm{N}=\left(\frac{\mathrm{a}+\mathrm{b}}{60}\right) \mathrm{xt}_{1}$ counter $(+10 \%)$ \\
\hline 6 & Tempat Duduk & $\mathrm{N}=\frac{1}{3} \cdot a$ \\
\hline 7 & Fasilitas Umum & $A=a \times 0,2 \times 1 m^{2}(+10 \%)$ \\
\hline 8 & Baggage Conveyor Belt & $\begin{array}{c}\mathrm{L}=\frac{\left(\sum \mathrm{p} \times \mathrm{n}\right)}{60 \text { menit }} \times 20 \text { menit } \\
=\frac{\left(\sum \mathrm{p} \times \mathrm{n}\right)}{3}\end{array}$ \\
\hline 9 & Baggage Claim Area & $\mathrm{A}=0,9 \mathrm{c}(+10 \%)$ \\
\hline 10 & Hall Kedatangan & $A=[0,375(b+c+2 \cdot c \cdot f)](+10 \%)$ \\
\hline
\end{tabular}

Dimana : $\mathrm{A}=$ Kebutuhan Luasan $\left(\mathrm{m}^{2}\right) ; \mathrm{a}=$ Jumlah penumpang pada waktu sibuk; $\mathrm{b}=$ Jumlah penumpang transfer; $\mathrm{f}=$ Jumlah pengantar penumpang (2 orang); $\mathrm{C}=$ Jumlah penumpang datang waktu sibuk; $U=$ Rata-rata menunggu selama $(0,6) ; \mathrm{i}=$ Proporsi penumpang menunggu terlama $(60$ menit); v = Rata-rata menunggu tercepat $(20$ menit); $\mathrm{k}=$ Proporsi penumpang menunggu tercepat $(0,4) ; \mathrm{t}_{1}=$ Waktu pemrosesan Check-in (2 menit/penumpang); $\mathrm{L}=$ Panjang Conveyor Belt

\section{Fasilitas Sisi Udara}

Dalam penyusunan standar teknis operasional fasilitas sisi udara ini, dibuat pengelompokan berdasarkan penggolongan pesawat dan kelas bandar udara di Indonesia seperti pada Tabel 3.

Tabel 3. Pengelompokan Bandar Udara Berdasarkan Kode Referensi Bandar Udara

\begin{tabular}{|l|l|l|l|l|}
\hline $\begin{array}{l}\text { Kelompok } \\
\text { Bandar Udara }\end{array}$ & $\begin{array}{l}\text { Kode } \\
\text { Angka }\end{array}$ & $\begin{array}{l}\text { ARFL } \\
\text { (Aeroplane Reference Field Length) }\end{array}$ & $\begin{array}{l}\text { Kode } \\
\text { Huruf }\end{array}$ & Bentang Sayap \\
\hline A (Unttended) & 1 & $<800 \mathrm{~m}$ & A & $<15 \mathrm{~m}$ \\
\hline B (AVIS) & 2 & $800 \mathrm{~m}<\mathrm{P}<1200 \mathrm{~m}$ & B & $15 \mathrm{~m}<1<24 \mathrm{~m}$ \\
\hline \multirow{3}{*}{ C (ADC) } & 3 & $1200 \mathrm{~m}<\mathrm{P}<1800 \mathrm{~m}$ & $\mathrm{C}$ & $24 \mathrm{~m}<1<36 \mathrm{~m}$ \\
\cline { 2 - 5 } & \multirow{2}{*}{4} & $\geq 1800 \mathrm{~m}$ & $\mathrm{D}$ & $36 \mathrm{~m}<1<52 \mathrm{~m}$ \\
\cline { 3 - 5 } & & & E & $52 \mathrm{~m}<1<65 \mathrm{~m}$ \\
\cline { 3 - 5 } & & & F & $65 \mathrm{~m}<1<80 \mathrm{~m}$ \\
\hline
\end{tabular}

\section{Pergerakan Pesawat Pada Jam Sibuk}

Untuk kondisi Indonesia menurut Japan International Coorporatian Agency (JICA), 1991 dengan persamaan berikut :

$$
\mathrm{Md} \quad=\frac{\mathrm{My}}{360}
$$




$$
\begin{array}{ll}
\mathrm{Cp} & =\frac{1,38}{\sqrt{\mathrm{Md}}} \\
\mathrm{Mp} & =\mathrm{Md} \times \mathrm{Cp}
\end{array}
$$

Dimana : Cp : Faktor jam puncak; Md : Pergerakan pesawat harian; Mp : Pergerakan pesawat pada jam puncak; My : Pergerakan pesawat tahunan

\section{Faktor - Faktor Yang Mempengaruhi Panjang Runway}

a. Ketinggian Altitude, ARFL bertambah 7\% setiap kenaikan $300 \mathrm{~m}$ dari permukaan laut

$$
\mathrm{Fe}=0,007(\mathrm{~h} / 300)
$$

Dimana $: \mathrm{Fe}=$ Faktor Koreksi Elevasi; $\mathrm{h}=$ Aerodrome Elevasi

b. Temperatur, ARFL bertambah $1 \%$ setiap kenaikan $1^{\circ} \mathrm{C}$,

$$
\begin{aligned}
& \mathrm{FT}=0,01(\operatorname{Tr}-0,0065 \mathrm{~h}) \\
& \mathrm{Tr}=\mathrm{T}_{1}+\frac{\mathrm{T}_{2}-\mathrm{T}_{1}}{3}
\end{aligned}
$$

Dimana $: \mathrm{FT}=$ Faktor Temperatur; $\mathrm{Tr}=$ Temperatur Aerodrome Referensi; $\mathrm{T}_{1}=$ Rerata temperatur harian pada bulan terpanas; $\mathrm{T}_{2}=$ Rerata temperatur maksimum harian pada bulan terpanas.

c. Kemiringan landas pacu, ARFL bertambah $10 \%$ setiap pertambah kemiringan

$$
\mathrm{Fs}=0,1 \times \mathrm{S}
$$

Dimana : Fs $=$ Faktor Koreksi kemiringan; $\mathrm{S}=$ Kemiringan

d. Panjang runway dibutuhkan (terkoreksi)

ARFL $x$ Fe $x$ Ft $x$ Fs

Lebar landas pacu (runway) haruslah tidak kurang dari ketentuan yang dipakai

\section{Taxiway/Penghubung Landasan Pacu}

Taxiway merupakan jalur penghubung dari runway ke apron ataupun sebaliknya dari apron ke runway. Lebar bagian lurus taxiway tidak boleh kurang dari standar yang telah ditentukan di dalam peraturan Direktur Jendral Perhubungan, Nomor : SKEP/77/VI/2005 tentang Persyaratan Teknis Pengoperasian Fasilitas Teknik Bandar Udara.

\section{Apron}

Tempat pelataran parkir pesawat harus tidak melanggar pembatas rintangan yang berada di permukaan dan terutama di dalam. Ukuran pelataran parkir pesawat harus cukup untuk dapat melayani arus lalu lintas maksimum yang diperlukan.

Untuk Persamaan yang digunakan untuk evaluasi kebutuhan apron berdasarkan Japan International Coorporatian Agency (JICA), adalah sebagai berikut :

$$
\mathrm{N}=\frac{\mathrm{cxt}}{60}+\mathrm{A}
$$

Dimana : $\mathrm{N}=$ Jumlah pesawat yang akan diparkir di apron; $\mathrm{c}=$ Jumlah gerakan pesawat pada jam sibuk; $\mathrm{t}=$ Waktu pesawat untuk menempati area parkir (30-60 menit); $\mathrm{A}=$ Cadangan pesawat.

Penentuan dimensi apron dapat sesuai dengan pelataran yang dibutuhkan adalah :

1. Panjang $(\mathrm{H})$
a. Clearance (c)
Clearance disesuaikan dengan ukuran klasifikasi Code Letter.
b. Jumlah Wingspan 
Panjang wingspan pesawat rencana terbesar dikalikan dengan jumlah pesawat yang akan menempati.

c. Jarak tepi apron ke pesawat terbang

Airport design membuat paraturan bahwa jarak taxiway (yang terletak pada pinggiran apron $)=11 / 2$ lebar taxiway atau dan arena ada 2 apron taxiway maka perlu dikalikan 2 . Sehingga panjang apron $(\mathrm{H})=$ clearance + jumlah wingspan + jarak tepi apron ke pesawat.

2. Lebar

a. Lebar service road (sr), lebar service road ditentukan $=10 \mathrm{~m}$

b. Panjang pesawat terbang / Aircraft length (paling panjang)

c. Clearance distance (ditentukan) disesuaikan dengan jenis pesawat

d. $\quad 0,5 \mathrm{x}$ wingspan (pesawat yang terbesar)

e. $\quad 1,5 \times$ lebar taxiway

f. $\quad$ sehingga lebar apron $(\mathrm{G})$

$(\mathrm{G})=\mathrm{Sr}+$ panjang pesawat + clearance distance $+0,5 \mathrm{x}$ wingspan pesawat terbesar $+1,5$ lebar taxiway

3. Jarak runway ke tepi apron

a. Jarak tepi strip sampai tepi ekor = tinggi pesawat $\mathrm{x}$ jumlah pesawat

b. Jarak minimum dari as runway sampai tepi ekor pesawat $=150 \mathrm{x}$ jarak as runway ke tepi apron

c. Jarak tepi apron sampai ekor pesawat $=$ clearance $+(0,5 \mathrm{x}$ wingspan $)+(1,5$ $\mathrm{x}$ lebar taxiway)

d. Jarak runway sampai tepi ekor pesawat $=$ Jarak minimum dari as runway sampai tepi ekor pesawat - Jarak tepi apron sampai ekor pesawat.

Perbedaan clearance distance antar pesawat setiap Bandar udara berbeda, sesuai dengan klasifikasi dari penggolongan Bandar udara tersebut. Berikut adalah ketetapan clearance distance berdasarkan penggolongan Bandar udara menurut ICAO

\section{Teori Peramalan (Forecasting)}

Untuk mengetahui persentase pertumbuhan, di rata-rata untuk menentukan persentase pertumbuhan di masa mendatang digunakan formula sebagai berikut:

$$
r_{n}=\frac{X n-(X n-1)}{(X n-1)} \times 100 \%
$$

Dimana $: \mathrm{rn} \quad=\quad$ Pertumbuhan penumpang tahun ke-n $(\%) ; \mathrm{Xn}=$ Jumlah penumpang tahun ke-n (penumpang/tahun); Xn-1 = Jumlah penumpang tahun sebelumnya (penumpang/tahun).

\section{Perhitungan Peak Hour Tahun Rencana}

Perhitungan Peak Hour Tahun rencana sesuai dengan tipikal penumpang dengan jumlah penumpang dan persentase dapat digambarkan seperti terlihat pada Tabel 4.

Tabel 4. Persentase TPHP (Typical Peak Hour Passanger)

\begin{tabular}{|l|l|l|}
\hline No. & Jumlah penumpang/tahun & Persentase TPHP (\%) \\
\hline 1 & $\geq 30.000 .000$ & 0,035 \\
\hline 2 & $20.000 .000-29.999 .999$ & 0,040 \\
\hline 3 & $10.000 .000-19.999 .999$ & 0,045 \\
\hline 4 & $1.000 .000-9.999 .999$ & 0,050 \\
\hline
\end{tabular}


JURNAL REKAYASA KONSTRUKSI MEKANIKA SIPIL (JRKMS)

\begin{tabular}{|l|l|l|}
\hline No. & Jumlah penumpang/tahun & Persentase TPHP (\%) \\
\hline 5 & $500.000-999.999$ & 0,080 \\
\hline 6 & $100.000-499.999$ & 0.130 \\
\hline 7 & $<100.000$ & 0.20 \\
\hline
\end{tabular}

Untuk lebih jelasnya, berikut merupakan persamaan untuk menentukan jumlah penumpang pada saat jam sibuk.

$$
\operatorname{Pn}=\text { Pox TPHP }
$$

Dimana : Pn $=$ Jumlah penumpang waktu sibuk rata-rata per hari pada tahun target (penumpang/hari); Po $=$ Jumlah penumpang tahunan pada tahun target (penumpang/tahun); TPHP = Typical Peak Hour Passenger

\section{Metode Peramalan (Forecast) Penumpang Tahun Rencana}

Ada beberapa macam cara perhitungan proyeksi pertumbuhan pernumpang. Pada penulisan tugas akhir ini, metode proyeksi yang digunakan adalah metode yang tidak memperhatikan komponen-komponen demografi yakni dengan menggunakan rumus pertumbuhan penumpang yaitu dengan persamaan aritmetik.

$$
\mathrm{P}_{\mathrm{n}}=\mathrm{P}_{\mathrm{o}}\{1+\mathrm{r} .(\mathrm{x})\}
$$

Dimana : Pn $=$ Jumlah penumpang setelah $\mathrm{n}$ tahun ke depan; $\mathrm{Po}=\quad$ Jumlah $\quad$ penumpang pada tahun awal; $r=$ Angka pertumbuhan penduduk; $x=$ Periode waktu proyeksi

\section{Metodologi}

Untuk mencapai agar dapat hasil sesuai dengan yang diteliti, digunakan metodologi penelitian seperti di gambarkan dengan alur pelaksanaan berikut.

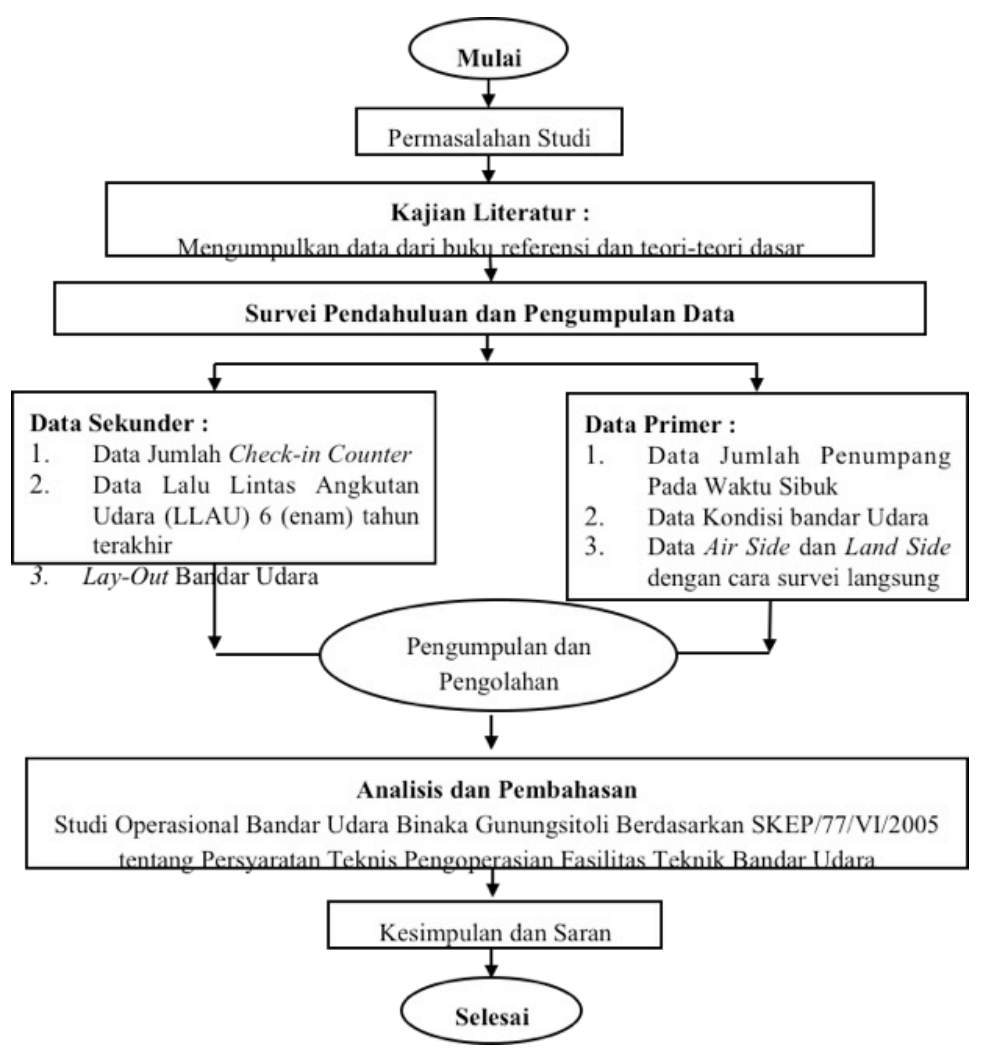

Gambar 1. Diagram Alir Penelitian 


\section{Analisis dan Pembahasan}

\section{Kondisi Pergerakan Penumpang dan Pesawat}

Kondisi pergerakan penumpang di Bandar Udara Binaka Gunungsitoli memiliki peningkatan rata-rata $8,55 \%$ setiap tahun, sementara pergerakan pesawat memiliki peningkatan rata-rata $8,77 \%$ setiap tahunnya. Jumlah penumpang pada jam puncak (peak hour) di dapatkan dari Bandar Udara Binaka Gunungsitoli. Jumlah pergerakan penumpang berangkat yaitu 166 penumpang dan yang datang 153 penumpang.

\section{Analisis Kondisi Eksisting Fasilitas Sisi Darat Bandar Udara Binaka Gunungsitoli}

\section{Fasilitas Keberangkatan}

Untuk mengetahui fasilitas keberangkatan Bandar Udara Binaka Gunungsitoli digunakan rumus berdasarkan ketentuan dalam Kepmen No. 20 Tahun 2005 tentang Pemberlakuan Standar Nasional Indonesia (SNI) 03-7046-2004, atau Peraturan Direktur Jenderal Perhubungan Udara Nomor : SKEP/77/VI/2005 tentang Persyaratan Teknis Pengoperasian Fasilitas Teknik Bandar Udara. Kebutuhan fasilitas terminal keberangkatan pada Bandara Binaka Gunung Sitoli diperoeh seperti pada Tabel 5. Dihasilkan kondisi eksising Bandara beradasarkan kebutuhan Fasilitas Terminal Keberangkatan tidak memenuhi Check-In Counter yang tersedia 2 sementara kebutuhan 7 dan Check-in Area yang tersedia 16 dimana kebutuhan 51,2 sesuai dengan standar bandara yang berlaku.

Tabel 5. Kebutuhan Fasilitas Terminal Keberangkatan Berdasarkan SKEP/77/VI/2005

\begin{tabular}{|l|l|l|l|l|}
\hline No. & Fasilitas & Eksisting & Kebutuhan & Keterangan \\
\hline 1 & Hall keberangkatan $\left(\mathrm{m}^{2}\right)$ & 497,2 & 419,1 & Memenuhi \\
\hline 2 & Ruang tunggu $\left(\mathrm{m}^{2}\right)$ & 717,75 & 180,9 & Memenuhi \\
\hline 3 & Check-in Counter & 2 & 7 & Tidak memenuhi \\
\hline 4 & Check-in Area & 16 & 51,2 & Tidak memenuhi \\
\hline 5 & Tempat duduk (buah) & 160 & 56 & Memenuhi \\
\hline 6 & Toilet & 160 & 36,5 & Memenuhi \\
\hline
\end{tabular}

\section{Fasilitas Kedatangan}

Untuk mengetahui fasilitas kedatangan Bandar Udara Binaka Gunungsitoli digunakan rumus berdasarkan ketentuan dalam Kepmen No. 20 Tahun 2005 tentang Pemberlakuan Standar Nasional Indonesia (SNI) 03-7046-2004, atau Peraturan Direktur Jenderal Perhubungan Udara Nomor : SKEP/77/VI/2005 tentang Persyaratan Teknis Pengoperasian Fasilitas Teknik Bandar Udara. Fasiltas kedatangan Bandara Binaka Gunung Sitoli diperoleh seperti pada Tabel 6. Hasil yang diperoleh dari kondisi eksisting faslitas kedatangan Bandara seluruh atribut berdasarkan peraturan memenuhi dengan kebutuhan.

Tabel 6. Fasilitas Kedatangan Bandar Udara Binaka Gunungsitoli Berdasarkan SKEP/77/VI/2005

\begin{tabular}{|l|l|l|l|l|}
\hline No. & Fasilitas & Eksisting & Kebutuhan & Keterangan \\
\hline 1 & Baggage Conveyor Belt $(\mathrm{m})$ & 13 & 10 & Memenuhi \\
\hline 2 & Baggage Claim Area $\left(\mathrm{m}^{2}\right)$ & 436,22 & 151,5 & Memenuhi \\
\hline 3 & Hall Kedatangan $\left(\mathrm{m}^{2}\right)$ & 338,8 & 104,4 & Memenuhi \\
\hline 4 & Toilet $\left(\mathrm{m}^{2}\right)$ & 53,5 & 33,7 & Memenuhi \\
\hline
\end{tabular}

\section{Analisis Kondisi Eksisting Fasilitas Sisi Darat Bandar Udara Binaka Gunungsitoli}

Dengan menggunakan data pergerakan pesawat pada tahun eksisting yaitu Tahun 2018, maka dapat diketahui kapasitas fasilitas sisi udara. Maskapai yang beroperasi di Bandar Udara Binaka Gunungsitoli yaitu Maskapai Garuda Indonesia dengan jenis pesawat Bombardier 
CRJ 1000 dan Maskapai Wings Air jenis pesawat ATR-72-600. Karena maskapai yang beroperasi hanya dua, maka analisis dilakukan permasing-masing maskapai atau jenis pesawat.

Penentuan Jam Puncak Pesawat

Jam puncak pesawat diperoleh hasil penelitian adalag seperti Tabel 7. Dengan hasil bahwa kondisi eksisting pergerakan pesawat harian 11 dengan 0,35 faktor jam puncak dengan jumlah pesawat 5 buah.

Tabel 7. Hasil Perhitungan Jam Puncak Pesawat

\begin{tabular}{|l|c|}
\hline Pergerakan pesawat udara harian $(M d)$ & 11 pergerakan \\
\hline Faktor jam puncak $(C p)$ & 0,39 \\
\hline Pergerakan pesawat jam puncak $(M p)$ & 5 pesawat \\
\hline
\end{tabular}

Data Pesawat Rencana

Data Pesawat sesuai spesifikasi teknis dengan Jenis Pesawat CRJ 1000 Next-Gen dan ATR 72-600 seperti pada Tabel 8 .

Tabel 8. Spesifikasi Teknis Pesawat CRJ 1000 Next-Gen dan ATR 72-600

\begin{tabular}{|l|l|l|}
\hline Karakteristik & CRJ 1000 & ATR 72-600 \\
\hline Take-Off Field Length & $1.996 \mathrm{~m}$ & $1.290 \mathrm{~m}$ \\
\hline Landing Field Length & $1.754 \mathrm{~m}$ & $914 \mathrm{~m}$ \\
\hline Berat Maksimum Lepas Landas (MTOW) & $40.824 \mathrm{~kg}$ & $22.800 \mathrm{~kg}$ \\
\hline Berat Kosong Operasi (Operating empty weigth) & $23.179 \mathrm{~kg}$ & $13.311 \mathrm{~kg}$ \\
\hline Berat Tanpa Bahan Bakar Maksimum (ZFW) & $35.154 \mathrm{~kg}$ & $20.800 \mathrm{~kg}$ \\
\hline Panjang (Length) & $39,1 \mathrm{~m}$ & $27,2 \mathrm{~m}$ \\
\hline Bentang Sayap (Wings Span) & $26,2 \mathrm{~m}$ & $27,05 \mathrm{~m}$ \\
\hline Tinggi (Heigth) & $7,5 \mathrm{~m}$ & $7,65 \mathrm{~m}$ \\
\hline Jarak roda (Wheelbase) & $9,7 \mathrm{~m}$ & $10,77 \mathrm{~m}$ \\
\hline Jarak Antar Roda Utama Terluar (OMGWS) & $7,14 \mathrm{~m}$ & $4,1 \mathrm{~m}$ \\
\hline
\end{tabular}

Hasil penelitian kebutuhan fasilitas sisi udara Bandara Binaka Gunungsitoli diperoleh Dimensi sesuai aturan ARC, Kategori Operasi dan fasilitas Runway, Fasilitas Taxiway dan Apron seperti dijelaskan pada Tabel 9, dimana panjang runway dan dimensi apron tidak memenuhi sesuai peraturan.

Tabel 9. Kebutuhan Fasilitas Sisi Udara Bandar Udara Binaka Gunungsitoli

\begin{tabular}{|l|l|l|l|l|}
\hline No. & Fasilitas & Eksisting & CRJ 1000 & Keterangan \\
\hline I & $\begin{array}{l}\text { Aerodrome Refence Code } \\
\text { (ARC) }\end{array}$ & $4 \mathrm{C}$ & $4 \mathrm{C}$ & Standar \\
\hline II & Kategori Operasi Runway & Non Instrumen & Non Instrumen & \\
\hline III & Fasilitas Landasan Pacu (Runway) & \\
\hline & Runway & $30 \mathrm{~m} \times 2.250$ & $45 \mathrm{~m} \times 2.333 \mathrm{~m}$ & Tidak memenuhi \\
\hline IV & Fasilitas Taxiway & $23 \mathrm{~m} \times 72 \mathrm{~m}$ & $18 \mathrm{~m}$ & Memenuhi \\
\hline & Dimensi Taxiway & $80 \mathrm{~m} \times 180 \mathrm{~m}$ & $154 \mathrm{~m} \times 136,3 \mathrm{~m}$ & Tidak memenuhi \\
\hline V & Fasilitas Apron & Dimensi Apron &
\end{tabular}


Perhitungan Peramalan (Forecast) Pergerakan Lalu Lintas Angkutan Udara (LLAU) Metode Peramalan (Forecasting)

Penelitian ini menggunakan metode proyeksi yang digunakan adalah metode yang tidak memperhatikan komponen-komponen demografi yakni dengan menggunakan rumus pertumbuhan penumpang yaitu dengan persamaan aritmetik, sperti dihasilkan pada Tabel 10.

Tabel 10. Hasil Proyeksi Penumpang Berangkat Tahun 2019 sampai 2038 dengan Metode Aritmetik

\begin{tabular}{|c|c|c|c|c|}
\hline \multirow{2}{*}{ No. } & \multirow{2}{*}{ Tahun } & Tahun ke, (x) & $\begin{array}{c}\text { Penumpang Berangkat } \\
\text { Pn=105722 }\{\mathbf{1 + 8 , 8 2 \% ( x )}\}\end{array}$ & $\begin{array}{c}\text { Penumpang Datang } \\
\text { Pn=101781 }\{\mathbf{1 + 8 , 3 9 \% ( x )}\}\end{array}$ \\
\hline 1 & 2013 & 0 & 105722 & 101781 \\
\hline 2 & 2014 & 1 & 115042 & 110320 \\
\hline 3 & 2015 & 2 & 124363 & 118860 \\
\hline 4 & 2016 & 3 & 133683 & 127399 \\
\hline 5 & 2017 & 4 & 143004 & 135939 \\
\hline 6 & 2018 & 5 & 152324 & 144478 \\
\hline 7 & 2019 & 6 & 161644 & 153018 \\
\hline 8 & 2020 & 7 & 170965 & 170096 \\
\hline 9 & 2021 & 8 & 180285 & 178636 \\
\hline 10 & 2022 & 9 & 189606 & 187175 \\
\hline 11 & 2023 & 10 & 198926 & 195715 \\
\hline 12 & 2024 & 11 & 208246 & \\
\hline
\end{tabular}

Perhitungan Peak Hour Tahun Rencana

Forecasting peak hour penumpang dilakukan menggunakan standar TPHP (Typical Peak Hour Passanger) dari FAA. Hasil perhitungan berdasarkan data penumpang yang terjadi pada Bandara Binaka Gunungsitoli setelah dilakukan forecasting, dituangkan pada Tabel 11. Perencanaan dengan peak hour dihasilkan pergerakan keberangkatan dan kedatangan terlihat pada Tahun 2024 terjadi 208.246 keberangkatan dengan peak hour 271 dan 195.715 kedatangan dengan peak hour 254.

Tabel 11. Hasil Perhitungan Peak Hour Setelah di Forecasting

\begin{tabular}{|c|c|c|c|c|c|c|}
\hline \multirow{2}{*}{ No } & \multirow{2}{*}{ Tahun } & \multicolumn{2}{|c|}{ Pergerakan Penumpang } & \multirow{2}{*}{ TPHP (\%) } & \multicolumn{2}{|c|}{ Peak Hour } \\
\cline { 3 - 4 } \cline { 6 - 6 } & & Berangkat & Datang & & Berangkat & Datang \\
\hline 1 & 2019 & 161644 & 153018 & 0,13 & 210 & 199 \\
\hline 2 & 2020 & 170965 & 161557 & 0,13 & 222 & 210 \\
\hline 3 & 2021 & 180285 & 170096 & 0,13 & 234 & 221 \\
\hline 4 & 2022 & 189606 & 178636 & 0,13 & 246 & 232 \\
\hline 5 & 2023 & 198926 & 187175 & 0,13 & 259 & 243 \\
\hline 6 & 2024 & 208246 & 195715 & 0,13 & 271 & 254 \\
\hline
\end{tabular}

\section{Analisis Sisi Darat Bandar Udara Binaka Gunungsitoli}

Kebutuhan luasan suatu terminal penumpang didasarkan pada jumlah penumpang tahunan yang akan dilayani oleh bandara tersebut pada tahun rencana. Berdasarkan hasil peramalan penumpang yang sudah dilakukan, dimulai pada Tahun 2024 jumlah penumpang tahunan yang akan dilayani oleh Bandar udara Binaka Gunungsitoli sudah mencapai 208.246 penumpang. Sehingga jumlah tersebut berpengaruh pada kebutuhan fasilitas Terminal Bandar udara.

\section{Terminal Penumpang Keberangkatan}

Setelah dilakukan analisis dan pengolahan data kebutuhan terminal keberangkatan Bandara Binaka Gunungsitoli hasilnya dituangkan pada Tabel 12. Maka yang perlu dikembangkan hall keberangkatan, Check-in Counter dan Check-in Area sesuai dengan peraturan. 
Tabel 12. Kebutuhan Terminal Keberangkatan Bandar Udara Binaka Gunungsitoli

\begin{tabular}{|l|l|l|l|l|}
\hline No & Fasilitas & Eksisting & Kebutuhan (2024) & Keterangan \\
\hline 1 & Hall keberangkatan $\left(\mathrm{m}^{2}\right)$ & 497,2 & 714,7 & Pengembangan \\
\hline 2 & Ruang tunggu $\left(\mathrm{m}^{2}\right)$ & 717,75 & 296,2 & Memenuhi \\
\hline 3 & Check-in Counter & 2 & 12 & Pengembangan \\
\hline 4 & Check-in Area $\left(\mathrm{m}^{2}\right)$ & 16 & 89,3 & Pengembangan \\
\hline 5 & Tempat duduk (buah) & 160 & 90 & Memenuhi \\
\hline 6 & Toilet $\left(\mathrm{m}^{2}\right)$ & 82,8 & 59,9 & Memenuhi \\
\hline
\end{tabular}

\section{Analisis Sisi Udara Bandar Udara Binaka Gunungsitoli}

Bandara ini dikembangkan dengan pesawat rencana Boeing 737-800 yang berkapasitas maksimum 189 penumpang untuk tahun rencana dimulai pada Tahun 2024. Dengan jumlah penumpang dan pergerakan pesawat yang akan direncakan Boeng 737-800 akan proyeksikan sesuai dengan data yang tersedia dari Tahun 2013 hingga Tahun 2024 diperoleh seperti dijelaskan pada Tabel 13.

Tabel 13. Proyeksi Peramalan Pergerakan Pesawat

\begin{tabular}{|c|c|c|c|}
\hline No. & Tahun & Tahun ke, (x) & $\begin{array}{c}\text { Pergerakan Pesawat } \\
\text { Pn= 1946 [1+8,83\% (x) }]\end{array}$ \\
\hline 1 & 2013 & 0 & 1946 \\
\hline 2 & 2014 & 1 & 2118 \\
\hline 3 & 2015 & 2 & 2290 \\
\hline 4 & 2016 & 3 & 2461 \\
\hline 5 & 2017 & 4 & 2633 \\
\hline 6 & 2018 & 5 & 2805 \\
\hline 7 & 2019 & 6 & 2977 \\
\hline 8 & 2020 & 7 & 3149 \\
\hline 9 & 2021 & 8 & 3320 \\
\hline 10 & 2022 & 9 & 3492 \\
\hline 11 & 2023 & 10 & 3664 \\
\hline $\mathbf{1 2}$ & $\mathbf{2 0 2 4}$ & $\mathbf{1 1}$ & $\mathbf{3 8 3 6}$ \\
\hline
\end{tabular}

\section{Pergerakan Pesawat pada Jam Sibuk}

Jam puncak pesawat diperoleh hasil penelitian adalah seperti Tabel 14. Dengan hasil bahwa kondisi pergerakan pesawat harian 11 dengan 0,42 faktor jam puncak dengan jumlah pesawat 5 buah.

Tabel 14. Hasil Perhitungan Jam Puncak Pesawat

\begin{tabular}{|l|c|}
\hline Pergerakan pesawat udara harian $(M d)$ & 11 pergerakan \\
\hline Faktor jam puncak $(C p)$ & 0,42 \\
\hline Pergerakan pesawat jam puncak $(M p)$ & 5 pesawat \\
\hline
\end{tabular}

Hasil penelitian kebutuhan fasilitas sisi udara Bandara Binaka Gunungsitoli diperoleh Dimensi sesuai aturan ARC, Kategori Operasi dan fasilitas Runway, Fasilitas Taxiway dan Apron seperti dijelaskan pada Tabel 15. 
JURNAL REKAYASA KONSTRUKSI MEKANIKA SiPIL (JRKMS)

Vol.3 No.1 April 2020

p-ISSN 2614-5707 e-ISSN 2715-1581

Tabel 15. Kebutuhan Fasilitas Sisi Udara Bandar Udara Binaka Gunungsitoli

\begin{tabular}{|l|l|l|l|l|}
\hline No. & Fasilitas & Eksisting & CRJ 1000 & Keterangan \\
\hline I & $\begin{array}{l}\text { Aerodrome Refence Code } \\
\text { (ARC) }\end{array}$ & $4 \mathrm{C}$ & $4 \mathrm{C}$ & Standar \\
\hline II & Kategori Operasi Runway & Non Instrumen & Non Instrumen & \\
\hline III & Fasilitas Landasan Pacu (Runway) & $30 \mathrm{~m} \times 2.250$ & $45 \mathrm{~m} \times 2.637 \mathrm{~m}$ & Pengembangan \\
\hline & Runway & $23 \mathrm{~m} \mathrm{x} 72 \mathrm{~m}$ & $18 \mathrm{~m}$ & Pengembangan \\
\hline IV & Fasilitas Taxiway & \multicolumn{5}{|l}{} \\
\hline & Dimensi Taxiway & $80 \mathrm{~m} \times 180 \mathrm{~m}$ & $209 \mathrm{~m} \times 156 \mathrm{~m}$ & Pengembangan \\
\hline V & Fasilitas Apron
\end{tabular}

\section{Kesimpulan}

- Kebutuhan fasilitas terminal kedatangan jumlah check-in counter tidak memenuhi standar berdasarkan Peraturan Dirjen Perhubungan No. SKEP/77/VI/2005. Kebutuhan check-in counter minimum pada jam sibuk diperoleh sebanyak 7 buah. Panjang landasan pacu (Runway) untuk pesawat jenis Bombardier CRJ 1000 sebesar 2.333 meter dengan lebar 45 meter.

- Penambahan pesawat dengan jenis Boeing 737-800 Tahun 2024, mengingat jumlah pergerakan pesawat sudah mencapai 11 kali dalam sehari. Jumlah pergerakan penumpang 403.961 penumpang, terdiri dari jumlah penumpang berangkat 208.246 orang dan penumpang yang datang 195.715 orang, dengan tingkat pertumbuhan pergerakan penumpang rata-rata sebesar $8,82 \%$ setiap tahunnya.

- Kebutuhan luas Hall Keberangkatan sebesar $724 \mathrm{~m}^{2}$ melebihi luas eksisting. Untuk check-in counter dan check-in area membutuhkan 12 buah meja check-in counter dengan luasan $90,5 \mathrm{~m}^{2}$, sehingga membutuhkan pengembangan.

- Kebutuhan Fasilitas Sisi Udara dengan dimensi landasan pacu untuk pesawat jenis Boeing 737-800 ialah 45 meter x 2.637 meter (Kondisi eksisting 30 meter x 2.250 meter). Lebar minimum untuk bagian lurus taxiway dengan pesawat Boeing 737-800 adalah 23 meter (Kondisi eksisting taxiway 23 meter). Dan dimensi apron 209 meter $\mathrm{x}$ 156 meter. (Dimensi eksisting 180 meter x 80 meter).

\section{Saran}

Beberapa saran yang dapat dijadikan bahan pertimbangan bagi pihak-pihak yang terkait antara lain :

- Mengantisipasi kondisi eksisting pada saat jam puncak agar mengarahkan penumpang yang telah melakukan check-in ke area ruang tunggu agar tidak terjadi penumpukan penumpang pada area check-in sehingga mempercepat sirkulasi penumpang pada area check-in. Maka perlu dilakukan analisis mengenai studi kinerja check-in counter terminal terhadap tingkat pelayanan penumpang.

- UPBU Bandar Udara Binaka Gunungsitoli agar melakukan penambahan fasilitas di sisi darat dan juga fasilitas di sisi udara, mengingat jumlah pergerakan penumpang dan pesawat yang semakin naik setiap tahunnya.

- Penelitian ini hanya membahas geometrik landasan pacu (runway), landasan hubung (taxiway) dan apron, tanpa menghitung struktur tebal perkerasannya

- Diperlukan penambahan pegawai untuk pemeriksaan penumpang berangkat pada jam sibuk sebagai solusi alternatif penambahan meja berdasarkan SKEP 77/VI/2005.

\section{Daftar Pustaka}

Anto, A. D. (2016). Pengembangan Fasilitas Sisi Udara Bandar Udara Blimbingsari Kabupaten Banyuwangi Menurut Standar Manual Aerodrome Bagian 139.

Basuki, H. (1986). Merancang Dan Merencanakan Lapangan Terbang. 
JURNAl REKAYASA Konstruksi MEKANiKA SiPIL (JRKMS)

Direktorat Jendral Perhubungan Udara. 2005. Persyaratan Teknis Pengoperasian Fasilitas Teknik Bandar Udara. (No.: SKEP/77/VI/2005)

Direktorat Jendral Perhubungan Udara. (2015). Standar Teknis Dan Operasi Peraturan Keselamatan Penerbangan Sipil - Bagian 139. (Nomor: Kp 39 Tahun 2015)

Horonjeff, R. (1998). Perencanaan dan Perancangan Bandar Udara, Edisi ketiga, Jilid 1, Penerjemah Ir. Budiarto Susanto, Penerbit Erlangga, Jakarta.

Kementerian Perhubungan Republik Indonesia. (1992). Kriteria Klasifikasi Bandar Udara (Kepmenhub No. KM 4 Tahun 1992).

Warsito, Djoko, 2017. "Manajemen Bandar Udara : Landasan Pacu, Taxiway dan Appron”. Erlanggga 